\title{
Improving Foreign Language Instruction with New Technologies and Universal Design for Learning
}

\author{
By Nicole Strangman, Anne Meyer, \\ Tracey Hall, and Patrick Proctor
}

As Ms. Garcia prepares Spanish lessons for her class of 20 ninth graders, she faces the same significant challenge that nearly all her colleagues do: how to meet the diverse learning needs and strengths of her students. One student, Cheryl, excels in most subjects but not Spanish class: she thinks it's boring and irrelevant, and she hates memorizing vocabulary. Antoine and Jacqui are both dyslexic, making it challenging for them to decode both English texts and the Spanish texts.

Ms. Garcia considers what goals, strategies and materials would help each student learn in the way that's best for him or her. What barriers do the usual classroom materials and tools present? What supports and additional resources would help students overcome those barriers so they can focus on learning? What would make her lesson more engaging? What options can she provide students to accommodate their individual styles and interests while still staying focused on learning content? What performance criteria are appropriate? What assessments will guide her efforts?

Teachers in today's classrooms face a significant challenge in trying to raise academic standards and improve outcomes for increasingly diverse populations of students, often in the face of strict accountability pressures. In addition, changes to special-education law during the past decade now mandate that all students, including those with disabilities, be given access to the same general education curriculum. Opportunities to learn are recognized as a civil right of all citizens. New approaches to planning and executing instruction are needed to ensure that all students have such opportunities. A single classroom may have students with very different backgrounds, skills, knowledge, and interests. Teachers know each student is unique and they want their students to succeed. They want to respond to individual differences by providing flexible and supportive learning environments. The question is how. 
Universal Design for

Learning: A Blueprint for Teaching Every Student
Of course, there are no simple answers. But educators can learn to develop and use flexible goals, methods, materials, and assessments to reach more learners without compromising high standards. Universal Design for Learning (UDL), an emerging approach to educational reform pioneered by the educational research group CAST, provides a blueprint for accomplishing this through the development of flexible, supportive learning environments (Meyer \& Rose, 1998; Rose \& Meyer, 2002). As new neuroscience technologies such as $\mathrm{AMRI}$ began to provide clearer understandings of how the learning brain functions, CAST's researchers realized that it was not the learners who were inadequate but rather the curriculum itself and that the curriculum must adapt to the student, not the other way around. By referring to this new approach as Universal Design for Learning, CAST's researchers were echoing the universal design movement in architecture and product development, which calls for designing structures, from office buildings to can openers, which will accommodate the needs of the greatest possible variety of users from the outset, without expensive or cumbersome retrofitting (Meyer \& Rose, 1998; Rose \& Meyer, 2002).

Drawing on new understandings of how the brain processes information and the complexities of individual learning, the UDL framework suggests guiding principles for the design of learning opportunities (Rose \& Meyer, 2000; 2002). These principles provide flexibility with respect to three primary areas of learning: recognition of the information to be learned, application of strategies to process that information, and engagement with the learning task (Vygotsky, 1962; see Table 1).

\begin{tabular}{|c|c|c|}
\hline RECOGNITION & STRATEGIC & AFFECTIVE \\
\hline The "what" of learning. & The "how" of learning. & The "why" of learning. \\
\hline $\begin{array}{l}\text { What are we seeing, } \\
\text { hearing, reading, } \\
\text { touching, etc., and } \\
\text { how best do we } \\
\text { categorize it? } \\
\text { Identifying letters, } \\
\text { words, or an author's } \\
\text { style are examples of } \\
\text { recognition tasks. }\end{array}$ & $\begin{array}{l}\text { How do we plan and } \\
\text { perform tasks, or } \\
\text { organize and express } \\
\text { our ideas? Writing an } \\
\text { essay and solving a } \\
\text { math problem are } \\
\text { strategic tasks. }\end{array}$ & $\begin{array}{l}\text { What engages and } \\
\text { motivates us in } \\
\text { learning? Are we } \\
\text { challenged, excited, } \\
\text { bored? What's the } \\
\text { point of our learning? }\end{array}$ \\
\hline
\end{tabular}


UDL Teaching Methods
CAST has also developed UDL teaching methods that provide teachers with some broad strategies to customize curriculum for individual learners by mapping instructional design to the three networks (Table 2). For example, the first UDL teaching method to support recognition learning is to provide multiple examples. This takes advantage of the fact that recognition networks can extract the defining features of a pattern and differentiate it from similar patterns simply by viewing multiple examples. This is one example of how digital materials and UDL teaching methods can facilitate successful UDL implementation.

TABle 2. Teaching Methods to Support UDL PRINCIPLES

To support diverse recognition networks:

- Provide multiple examples

- Highlight critical features

- Provide multiple media and formats

- Support background context

To support diverse strategic networks:

- Provide flexible models of skilled performance

- Provide opportunities to practice with supports

- Provide ongoing, relevant feedback

- Offer flexible opportunities for demonstrating skill

To support diverse affective networks:

- Offer choices of content and tools

- Offer adjustable levels of challenge

- Offer choices of rewards

- Offer choices of learning context

- UDL calls for providing:

Source: Rose \& Meyer, 2002. 
1) Multiple, flexible methods of presentation in order to support diverse recognition networks. Providing students multiple examples of a pattern helps them to extract the key features and offers them the chance to select and focus on the examples that are most effective for them. Students vary in their ability to process different patterns, making it essential that teachers use different media and formats during instruction. This might mean showing students text, images, and video as well as immersing students in field experiences. For example, the content of a lesson on foods of France could be presented as printed text, text in digital format (with an option for text-to-speech, Braille and variable display formats), images, and video-or by actually preparing and eating French food.

2) Providing multiple, flexible methods of expression and apprenticeship in order to support diverse strategic networks. Students' strengths, weaknesses, and preferences in the area of strategic learning vary as widely as they do for recognition learning. Thus, it is equally important to offer multiple, flexible opportunities and methods for expression and apprenticeship when students are working to figure out what they are expected to learn and demonstrating what they know. Just as students can extract critical features of a pattern from multiple examples, so can they can also extract the critical features of a process with multiple models. In addition, complex skills and texts are easier to master when their component steps or parts are presented. Offering students the chance to practice with scaffolds can facilitate that process. Depending on the learner's level of need and preferences, scaffolds could take many forms, including graphic organizers with clusters of related vocabulary words to visually demonstrate their relationship; one-on-one review with the teacher; or access to peer expertise through cooperative work such as developing a story.

As students continue to practice, it is also essential to provide ongoing, relevant feedback. This, too, takes a variety of forms to meet different students' needs and preferences: one on one teacher or peer feedback, a group discussion to reveal gaps in knowledge or misconceptions or skill deficits, or perhaps a self-test. When it comes time for assessment, skill and knowledge demonstration helps to ensure that students' performances reflect what they actually know and can do rather than how good they are at, say, taking a test. For example, when testing understanding of Spanish vocabulary, a teacher could offer students flexible options for demonstrating knowledge or skill, such as answering multiple choice questions, composing essays or writing their own Mexican folk song, selecting critical features from a picture series, composing scrapbooks of vocabulary exemplars, or giving oral presentations.

3) Providing multiple, flexible options for engagement in order to sup- 


\section{Feature}

UDL Planning Process port diverse affective networks. Students vary widely in their preferences and inclinations, making it important to give students the flexibility of pursuing their own interests and provide multiple, flexible options for engagement. Offering choices of content and tools is one way for teachers to fuel every student's enthusiasm. Although by design the content area is often restricted, in some cases there is leeway to offer students choice. With respect to tools, students might be given the option of working with many different media. For example, a lesson about the history of French-speaking Canada could allow the students to learn about that history by reading oral histories, watching a PBS documentary on the subject, exploring relevant websites, interviewing an expert from a nearby college, or conducting an historical scavenger hunt to collect clues to the region's development. Challenge is another factor influencing students' motivation to learn. When challenged too much or too little, students tend to disengage. But by providing adjustable levels of challenge teachers can help ensure that each student is optimally motivated.

Of course, curriculum planning and delivery is critical to making these Teaching Methods work. To begin, we recommend that teachers have a basic understanding of UDL, and a commitment to make the curriculum and learning accessible for all learners. While keeping in mind the three principles of UDL, based on recognition, strategic and affective networks, we have found the following process useful in designing lessons. The process includes four steps based upon the principles and concepts of UDL, proven professional development strategies, and effective teaching practices; (a) Set Goals, (b) Analyze Status, (c) Apply UDL, and (d) Teach the UDL Lesson (Figure 1).

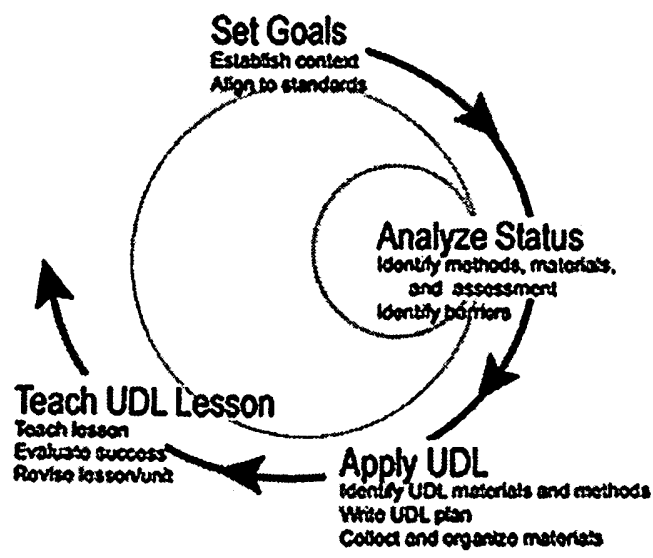

Figure 1. A UDL Planning Model 
To Set Goals, teachers may want to establish the context for instruction. Context is usually driven or based on state standards, followed by the design of goals for the instructional episode. We recommend that all teachers closely evaluate these to assure alignment as well as a clear separation between goals and standards and the means for attaining them.

Next, when designing a UDL lesson, teachers will find it useful to Analyze the Current Status of the instructional episode. What are the current methodologies, assessments, and materials used to teach the lesson? Do all students have access to the materials? Are students able to express themselves with the current methods and materials?

Step three is to Apply UDL to the Lesson/Unit. This includes the goals, methods, assessments and materials used to implement the lesson. Teachers will want to create a UDL lesson plan that is grounded in the learning goals, classroom profile, methods and assessment, and materials and tools. They then will work to collect and organize materials that support the UDL lesson.

In the final step, Teach the UDL Lesson/Unit, teachers minimize barriers and realize the strengths and challenges each student brings to learning, rely on effective teaching practices, and apply challenges appropriate for each learner. In this way, instructors can engage more students and help them all to progress. When teaching and evaluating student work, also evaluate and revise the lesson/unit to assure student access and success. (Note: Additional information and models of UDL practice are available in the book Teaching Every Student in the Digital Age by Rose \& Meyer [2002], and at its companion website www.cast.org/teachingeverystudent.)

Digital Technology and UDL: A Potent Combination
Though not a technology-based approach per se, UDL is most powerful when paired with technology tools. Digital materials such as electronic text offer indispensable support for UDL implementation because their inherent flexibility enables them to be modified in a host of ways. This flexibility makes it possible to customize learning materials and methods to each individual, depending on his or her needs. For example, although providing multiple representations might be challenging in a classroom limited to printed text and hard copy images, digital materials enable the assembly, storage, and maintenance of a large collection of examples in the form of digital text, images, sound, or video-all in the modest space of a classroom.

In contrast with fixed formats of print, electronic text can easily be transformed in its visual presentation (the size, color, shape, layout of text elements) and even can be easily transformed into other modalities and languages (e.g. text to speech, text to refreshable Braille, text to American Sign Language, text to second language). 
Digital content can contain media elements other than printed text, including images, audio, video, etc. Some of those, like video, which cannot be included in printed text, add great variability to learning materials. Also, the "associative" quality of digital material-as compared with the "linear" quality of printed text-makes it more useful to a greater variety of learners. Printed elements appear in a preferential sequence, whereas digital materials, including electronic text, can be "linked" in many ways (such as hypertext), creating many alternative sequences and structures that can accommodate a greater diversity of learners.

Of course, not all digital formats are flexible. For example, imagebased PDF files are formatted to preclude the common transformations (like text-to-speech) and presentational options that are essential for accessibility. Some others are embedded within images and are therefore not available for transformation. Web pages often display this type of inflexible and inaccessible content. Others, like ASCII, lack sufficient structural markup to provide an adequate basis for the kinds of customization needed by many students with disabilities. But in general, digital materials offer formidable advantages over the kinds of printed curricular materials that dominate most classroom settings.

Technology-Enriched UDL and Foreign Language Learning
Do technology-enriched UDL approaches offer a helpful framework for current foreign language teaching and learning? An informal survey of recent literature on foreign language learning (L2)-combined with observations from CAST's two decades of UDL research, including the development of digital learning environments to support English Language Learners (ELLs)—suggests that it could be useful.

Already many teachers in the foreign language field have moved toward the sort of individualized, highly contextualized learning approaches that UDL has been shown to effectively support. For example, foreign language practice, and especially computer-based practice, has moved away from isolated skills instruction-such as drill-and-practice in vocabulary, grammar, and pronunciationtoward a greater focus on communicative proficiency and the use of culturally authentic texts or learning in culturally relevant contexts (Access ERIC 1998). Liaw (1998) writes that while computers were originally used in L2 primarily to provide practice in languages, this paradigm has shifted with the advent of advanced communications technologies so that computers and computer networks now fulfill a "primary function as enablers of authentic and natural language use" (336).

Along these lines, vocabulary acquisition has long been shown to be of major importance in reading, speaking, and listening (Anderson \& Freebody 1983). While traditional direct instruction of individual 
words has not been shown to be a powerful means of generating high degrees of word knowledge, richer, technology-based techniques have been employed to facilitate the means by which foreign language-learning children may increase their L2 vocabularies. For example, Laufer (2003), in a series of experiments with adolescent and adult English-as-a-foreign-language learners, found that students who were required to interact with words (through writing) were significantly more likely to understand and retain a word's meaning after a delay in testing. The conclusion is that for second language learners (and perhaps for most readers), the amount of cognitive energy expended to understand a word's meaning is directly related to its retention.

Twenty-first century communications technologies offer powerful means to provide contextualized language use through local and global student-student and student-teacher interactions. Email, blogs, chatrooms and other such tools and venues provide powerful connections among students and teachers across the globe, breaking down geographic and linguistic barriers, and facilitating communicative proficiency (LeLoup and Ponterio 1998; Rennebohm, Franz \& Gragert 2003). Other technologies for L2 include interactive games with speech recognition technology so students can hear how they sound; reference packages with dictionaries, atlases, and encyclopedias; authoring programs that help teachers to develop multimedia language materials that leverage audio, video, and satellite technologies; and so forth (Earp 1997).

These tools are having an impact on foreign language instruction around the globe. Pufahl, Rhodes \& Christian (2001) surveyed teachers in 19 countries outside the U.S. about elementary and secondary foreign language instruction. Teachers' answers to the question "What do you think are three of the most successful aspects of foreign language education in your country?" reflected the need for a "comprehensive use of technology: technology as a way to provide access to information, give students an opportunity to interact with speakers of a foreign language, and to engage students ..." (3).

These technologies can all be used to support the three brain networks identified in the UDL framework-recognition, strategic, and affective-by providing multiple means of representation, expression, and engagement. UDL's emphasis on ensuring the relevancy of learning goals and contexts, providing multiple media options for learning, and supporting students' individual learning needs and preferences is compatible with the changing L2 field, particularly as it relates to technology use.

Furthermore, the UDL framework and teaching methods complement and support the National Standards in Foreign Language. For 
example, the Standards call for student communications that are conversational, provide and obtain information, express feelings and emotions, and exchange opinions (National Standards 1996). In other words, it is necessary to use language as naturalistically as possible, which offers students a better contextual understanding of what they are learning as well as a reason to be engaged in their learning. The standards also call for students to "reinforce and further their knowledge of other disciplines through the foreign language" (Standard 3.1). Such an interdisciplinary approach is compatible with the call for multiple means of representation, expression, and engagement by extending the variety of contexts, methods, and approaches to foreign language learning. The Standard calling for students to "show evidence of becoming lifelong learners by using the language for personal enjoyment and enrichment" (Standard 5.2) is especially consonant with UDL, which emphasizes the development of usable knowledge and knowledge-building strategies, as well as engagement.

Digital texts make it possible to embed strategy instruction and metacognitive supports directly into texts (Dalton \& Strangman, in press; Rose \& Meyer 2002; Strangman 2003; Strangman \& Dalton 2005), something Cohen (2003) has identified as effective for teaching L2 learners reading comprehension strategies using foreign-language texts. Cohen identifies the goals of strategy training (in context of second language instruction) as helping students to 1) identify strengths and weaknesses, 2) develop metacognitive knowledge of what helps them learn a foreign language effectively, 3 ) develop problem-solving skills, 4) experiment with familiar and unfamiliar learning strategies, 5) make decisions about how to approach a language learning task, 6) self-monitor and evaluate, and 7) transfer strategies to new contexts.

Chun and Plass (1996a; 1996b; 1997) have found that the use of multimedia vocabulary annotations, including audio, graphics, and animated pictures or video, contribute to vocabulary acquisition and in overall text comprehension. In one study of 160 university students learning German, they found that the inclusion of multimedia annotations-visual and verbal-facilitated reading comprehension more than just verbal annotations did.

An Example: Universal Learning Editions
In recent years, CAST's research has focused on the use of digital texts with embedded scaffolds in supporting diverse learners' literacy achievement-particularly in its research and development of Universal Learning Editions (ULEs), which are digital learning environments that have a host of supports that make high-quality literature truly accessible and useful for learners across a wide spectrum of ability and disability (Dalton, Pisha, Coyne, Eagleton, \& Deysher 2002; Gordon 2002; Rose \& Meyer 2002). In developing ULEs, 
CAST applied research on reading comprehension instruction, specifically reciprocal teaching (Palincsar \& Brown 1984) and UDL, to the design of interactive digital texts with embedded strategy instruction. Students with decoding and fluency problems can use text-to-speech to have individual words or passages read aloud with synchronized highlighting. To support the development of reading comprehension, strategy instruction prompts are embedded in the digital text and hints, thinkalouds and model responses are provided on demand by animated, virtual coaches. Strategy support is leveled so that students move from high to low support, with the goal of independent application of strategies. For example, at level 1, students select a good summary from 3 multiple choice options; at level 2 , they review a list of points from the passage and identify the "important" ones; at level 3, students construct a summary using highlighted text in the passage and complete a self-check rubric; at level 4, students create a summary and complete the self-check rubric; and at level 5, students choose a strategy that they feel would be most helpful. Students' online responses are collected in a computer worklog for review and evaluation by the student and the teacher.

Engagement is addressed in multiple ways. Key factors include: using on-grade level texts so students are reading at their interest level, rather than their decoding level (TTS makes this possible); allowing students to choose which supports to access, such as computer agent strategy coaches, hyperlinked vocabulary, and background knowledge; providing students with frequent opportunities for self-reflection; and situating the ULE within the larger classroom context by giving students opportunities to discuss the ULE texts and share their insights about strategic reading.

Table 3 offers further examples of how the Universal Learning Editions can support the development of essential background knowledge for struggling middle-school readers, including Spanishspeaking English language learners. 


\begin{tabular}{|c|c|}
\hline UDL Teaching Method & Supportive Lesson Feature(s) \\
\hline Provide multiple examples. & $\begin{array}{l}\text { The multimedia glossary offers } \\
\text { multiple photo illustrations for } \\
\text { vocabulary words. Web links to } \\
\text { resources offer students multiple } \\
\text { examples of key facts and concepts. }\end{array}$ \\
\hline Highlight critical features. & $\begin{array}{l}\text { The Maps, Timeline, and } \\
\text { Character Journey highlight } \\
\text { critical features of the text related } \\
\text { to setting and characters. The } \\
\text { PowerPoint and Web links to } \\
\text { resources highlight other critical } \\
\text { features related to the text. }\end{array}$ \\
\hline $\begin{array}{l}\text { Provide multiple media } \\
\text { and formats. }\end{array}$ & $\begin{array}{l}\text { The multimedia glossary offers text } \\
\text { and illustrations. The video and } \\
\text { photo essay provide redundant } \\
\text { information in multiple media and } \\
\text { formats. Maps and Character } \\
\text { Journey present story information } \\
\text { in another medium and format. } \\
\text { Vocabulary support is provided in } \\
\text { English and Spanish. }\end{array}$ \\
\hline $\begin{array}{l}\text { Provide opportunities to practice } \\
\text { with supports. }\end{array}$ & $\begin{array}{l}\text { All the background knowledge } \\
\text { aids provide optional support for } \\
\text { students, who can access them or } \\
\text { not, as they wish. }\end{array}$ \\
\hline Offer adjustable levels of challenge. & $\begin{array}{l}\text { Students can adjust the level } \\
\text { of challenge by varying their } \\
\text { consultation of the background } \\
\text { knowledge supports. }\end{array}$ \\
\hline Offer choices of content and tools. & $\begin{array}{l}\text { The variety of background knowl- } \\
\text { edge aids provide students with } \\
\text { the opportunity to choose among } \\
\text { different content and tools. }\end{array}$ \\
\hline
\end{tabular}

Dalton and colleagues (2002) compared traditional classroombased strategy instruction with a comparable condition reading ULE versions of the texts. In the three-year study, 102 middle school students in both conditions used the reciprocal teaching strategies of predict, question, clarify and summarize (Palincsar \& Brown 1984), as well as visualization (Pressley 1998). After controlling for gender and initial reading achievement, students in the ULE condition demonstrated significantly greater gains on a standardized measure of reading comprehension than did their peers in the traditional strategy instruction condition. The effect size was moder- 
ate, equating to approximately half a grade level of reading achievement gain. For struggling readers who read at or below the $25^{\text {th }}$ percentile prior to intervention, however, this was a meaningful increase. The finding that students with relatively higher initial vocabulary versus comprehension scores demonstrated greater comprehension gains was particularly important, and suggested the need to improve the quality of the ULE vocabulary experience.

Extending this work to Spanish-speaking English language learners, refinements to the ULEs have targeted vocabulary enrichment supports and Spanish-language translation options (see Figure 2). Proctor, Dalton, and Grisham (in submission) piloted a combined vocabulary and strategy ULE in a classroom of 30 fourth-grade students consisting of 14 Spanish-speaking ELLs and 16 monolingual English speakers. The tested ULE had an event usage log tracker that recorded and stored each student's interactions with the ULE supports. Of particular interest to the proposed work was the finding that lower-performing students, including ELLs, were more likely to access important vocabulary (clicking hyperlinked vocabulary words and posting them to "My Glossary") and comprehension supports (accessing strategy coach support), shown in Figure 2. After controlling for pretest reading vocabulary and comprehension, the use of vocabulary features was significantly associated with gains in vocabulary, while accessing strategy coach support was approaching significance for comprehension gains. Analyses of individual student responses suggested that participants who made use of these supports were interacting meaningfully with the texts.

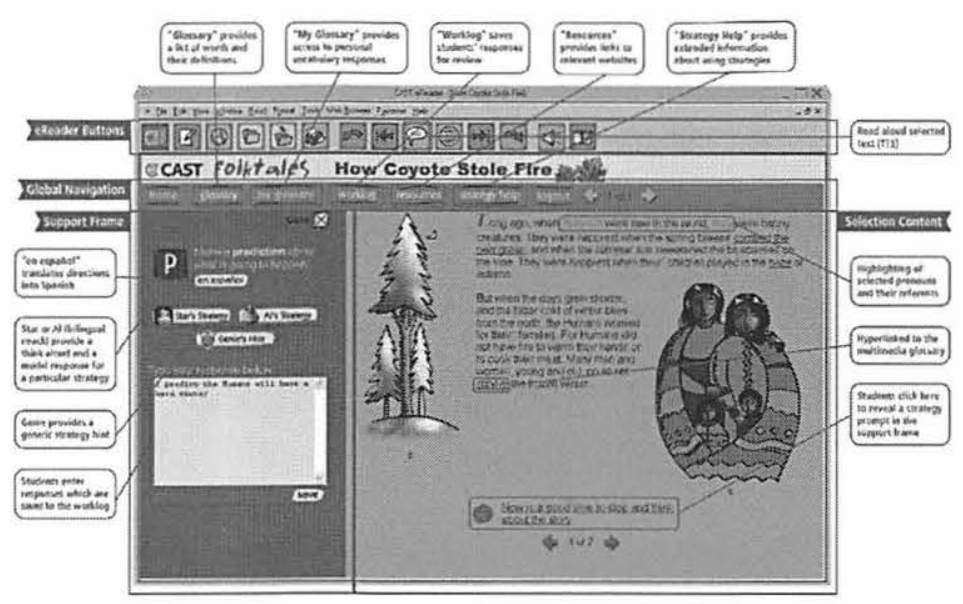

Figure 2. Screenshot of UDE environment with various features highlighted 


\section{Conclusion}

Works Consulted
In a new study (2005-2007) funded by the U.S. Department of Education's Institute of Educational Sciences, researchers at CAST and Harvard University are exploring ways to enhance the ULE with more robust vocabulary supports with the goal of improving students' reading comprehension and vocabulary outcomes. Of particular interest is whether use of the embedded comprehension supports are associated with vocabulary and comprehension outcomes over the course of the intervention. Additionally, learner characteristics (e.g., struggling reader and ELL status) are being assessed to determine if students who typically struggle with text comprehension are more likely to access the various supports as Proctor and colleagues found. These data will yield critically important information relevant to the design and use of individualized digital learning environments for second language learning.

Universal Design for Learning provides a potent framework for teachers like Ms. Garcia as she works to meet the needs of diverse learners, especially when UDL is employed in combination with developing technologies. Together, UDL and new technologies can facilitate the efforts to generate more flexible and broadly accessible curricula, and provide teachers with both theory and practice to appropriately challenge the broad scope of students in classrooms today. Although educators are continually challenged by the everchanging classroom profile of students, resources, and reforms, universally designed approaches offer a way to meet that challenge in ways that truly support the teaching and learning of all students.

Note: This paper draws on and extends material previously published as "UDL Implementation: Examples Using Best Practices and Curriculum Enhancements," in D.H. Rose, A. Meyer, and C. Hitchcock (Eds.) 2005. The Universally Designed Classroom: Accessible Curriculum and Digital Technologies. Cambridge, MA: Harvard Education Press. For more information, visit http://gseweb.harvard.edu/ hepg/

ACCESS ERIC. 1998. K-12 foreign language instruction. The ERIC review 6, 1. Rockville, MD: Author. ERIC Document Reproduction Service No. ED 437930

Anderson, R.C., \& Freebody, P. 1983. Reading comprehension and the assessment and acquisition of word knowledge. In B. Huston (Ed.), Advances in reading/language research (Vol. 2, pp. 231-56). Greenwich, CT: JAI Press.

Chun, D., \& Plass, J. 1996. Effects of multimedia annotations on vocabulary acquisition. The Modern Language Journal, 80(2), 183-198. 
Chun, D. M. \& Plass, J. L. 1996b. Facilitating reading comprehension with multimedia. System, 24 (4), 503-519.

Chun, D.M., \& Plass, J.L. 1997. Research on text comprehension in multimedia environments. Language Learning o Technology 1(1), 60-81

Cohen, A. 2003. Strategy training for second language learners: ERIC digest. Washington, DC: Eric Clearinghouse on Language and Linguistics. ERIC Document Reproduction Service No. 482492.

Dalton, B., Pisha, B., Eagleton, M., Coyne, P., and Deysher, S. 2002. Engaging the text:

Reciprocal teaching and questioning strategies in a scaffolded learning environment. Final Project Report. Project funded by U.S. Office of Special Education Programs. Peabody, MA: CAST.

Dalton, B., \& Strangman, N. (in press). Improving struggling readers' comprehension through scaffolded hypertexts and other computer-based literacy programs. To appear in D. Reinking, M.C. McKenna, L. D. Labbo, \& R.D. Keiffer (Eds.), Handbook of literacy and technology. (2nd ed.), Mahwah, NJ: Lawrence Earlbaum Publishers.

Earp, S. 1997. More than just the internet: Technology for language teaching: ERIC digest. Washington, DC: ERIC Clearinghouse on Language and Linguistics. ERIC Document Reproduction Service No. ED 414767.

Gordon, D. T. 2002. Curriculum access in the Digital Age: New technology-based strategies offer hope that students of all abilities will have the opportunity to thrive in school. Harvard Education Letter, 18(1):1-5.

Hall, T., Meyer, A., \& Strangman, N. UDL implementation: Examples using best practices and curriculum enhancements. In D.H. Rose, A. Meyer, and C. Hitchcock (Eds.) 2005. The Universally designed classroom: Accessible curriculum and digital technologies Cambridge, MA: Harvard Education Press.

Laufer, B. 2003. Vocabulary acquisition in a second language: Do learners really acquire most vocabulary by reading? Some empirical evidence. Canadian Modern Language Review, 59(4), 567-87.

LeLoup, J., \& Ponterio, R. 1998. Meeting the national standards: Now what do I do?: ERIC digest. Washington, DC: Eric Clearinghouse on Language and Linguistics. ERIC Document Reproduction Service No. ED 425657 
Liaw, M. 1998. Using electronic mail for English as a foreign language instruction. System 26(3), 335-351

Meyer, A., \& Rose, D.H. 1998. Learning to read in the computer age. Cambridge, MA: Brookline Books.

National Standards in Foreign Language Education Project. 1999. Standards for foreign language learning: Preparing for the $21^{\text {st }}$ century. Yonkers, NY: Author. ERIC Document Reproduction Service No. ED 394279.

Palinscar, A. S., \& Brown, A. L. 1984. Reciprocal teaching of comprehension-fostering and comprehension-monitoring activities., Cognition \& Instruction (Vol. 1, pp. 117): Lawrence Erlbaum Associates.

Pressley, M. 1998. Reading instruction that works: The case for balanced teaching. New York: Guilford Press.

Proctor, P., Dalton, B. \& Grisham, D. (in submission). Scaffolding English language learners and struggling readers in a digital environment with embedded strategy instruction and vocabulary support.

Pufahl, I., Rhodes, N.C., \& Christian, D. 2001. What we can learn from foreign language learning in other countries: ERIC digest. Washington, DC: Eric Clearinghouse on Language and Linguistics. ERIC Document Reproduction Service No. ED 456671.

Rennebohm Franz, K., \& Gragert, E. 2003. "Global education for today's world: Creating hope with online learning communities." In D.T. Gordon (Ed.) Better Teaching and Learning in the Digital Classroom. Cambridge, MA: Harvard Education Press.

Rose, D., \& Meyer, A. 2000. Universal design for individual differences. Educational leadership, 58(3), 39-43.

Rose, D. H., \& Meyer, A. 2002. Teaching every student in the digital age: Universal Design for Learning. Alexandria, VA: ASCD.

Strangman, N. 2003. Strategy instruction goes digital: Two teachers' perspectives on digital texts with embedded learning supports. Reading Online 6(9). Retrieved October 14, 2005, from http://www.readingonline.org/articles/art_index.asp?HREF= /articles/voices/winslow_previte/ 
Strangman, Meyer, Hall, and Proctor

Strangman, N., \& Dalton, B. 2005. Technology for struggling readers: A review of the research. In D. Edyburn et al (Eds). The Handbook of Special Education Technology Research and Practice. Whitefish Bay, WI: Knowledge by Design: 545-569.

Vygotsky, L. 1962. Thought and language. Cambridge, MA: MIT Press. 